\title{
Active Life Expectancy and Functional Health Transition among Filipino Older People
}

\author{
Grace T. Cruz \\ Population Institute \\ University of the Philippines \\ Quezon City, Philippines \\ gustcruz@yahoo.com \\ Yasuhiko Saito \\ Center for Information Networking \\ Nihon University \\ Tokyo, Japan \\ Josefina N. Natividad \\ Population Institute \\ University of the Philippines \\ Quezon City, Philippines
}

\begin{abstract}
The study provides a baseline information on the functional health transition patterns of older people and computes for the Active Life Expectancy (ALE) using a multistate life table method. Findings on ALE demonstrate that females and urban residents live longer and have a greater proportion of their remaining life in active state compared to their counterparts. Health transition analysis indicates a significant proportion experiencing recovery. Age, sex, place of residence and health status/behavior indicators (self-assessed health, drinking and exercise) display a significant influence on future health and mortality trajectories although surprisingly, education did not show any significant effect.
\end{abstract}

Key Words: Active life expectancy, Filipino, functional change, functional survey data 
Grace T. Cruz, Yasuhiko Saito and Josefina N. Natividad

\section{Résumé}

Cette étude présente une base de données sur les tendances fonctionnelles des changements d'état de santé chez les personnes âgées et analyse l'espérance de vie active (EVA) en utilisant une méthode de table de survie multiple. Les résultats de l'EVA démontrent que les femmes et les résidents urbains vivent plus longtemps et passent une plus grande proportion de la fin de leur vie dans un état d'activité que leurs homologues. L'analyse des changements d'état de santé indique qu'une proportion importante d'entre eux se rétablit suite à une maladie. L'âge, le sexe, le lieu de résidence, l'état et les habitudes de santé (auto-évaluation de la santé, consommation d'alcool et exercice) ont une influence importante sur l'état de santé futur et la trajectoire de mortalité bien que, et ceci est surprenant, le niveau d'éducation semble ne pas avoir d'impact important.

Mots-clés : Espérance de vie active, Philippins, changements fonctionnels, données d'étude fonctionnelles

\section{Introduction}

The rate of aging in the Philippines is slow in comparison with that of other countries which have experienced more dramatic demographic changes but the absolute number of older people is not small and is projected to substantially increase in the future. At the same time, studies indicate evidence of an increased incidence of disability associated with advanced old age (Freedman et al., 2002). This means that success in adding years to life does not necessarily mean adding life to years, creating fears that the extended years of life will simply be spent in ill health and in disability (Verbrugge, 1984; Olshansky and Ault, 1986; Crimmins et al., 1997). This pattern implies that the projected expansion in the size of the older population is likely to mean a corresponding increase in the number with disability. This future scenario has thus elevated health, particularly health expectancy as a central issue in the discussion of aging.

In the Philippines, the concept of active life expectancy (ALE) is relatively new. Little is known on the level of ALE, its differentials across socioeconomic, demographic settings and the functional health transition patterns among older people. Using the first panel data on older people ages 50 years 
and over, the present research tries to address these information gaps by analyzing the patterns and determinants of transitions in functional health states among Filipino older people. Functional health transitions are examined in consideration of competing risks including mortality and longitudinal attrition. Then ALE by subgroups of the population based on the results from multistate life table (MSLT) method are estimated.

\section{Background}

Health Expectancy (HE) is a generic term typically referring to the average number of years an individual can expect to live in a given health state (Mathers, Robine and Wikins, 1994). An attractive feature of HE is that it combines the fundamental dimensions of health (mortality, morbidity and disability) into a summary indicator to provide information on the length of life and the healthfulness of life. It shares other important properties with life expectancy (LE) such as independence from the age structure of the population and its measurement in expected years of life (Nusselder and Looman, 2004). The concept of HE resulted from a broadening in the conceptualization of health from a metric (which uses length of life as a measure of health status) to a quality of life perspective. HE is often called ALE when Activities of Daily Living (ADL) and Instrumental Activities of Daily Living (IADL) are used as measures of health status. Specifically, ALE measures health in terms of functional ability, not disease status.

Research on health expectancy underscores the significance of age, sex and socioeconomic status as predictors of health expectancy (Crimmins, Hayward and Saito, 1996; Liu et al. 1995; Hayward and Heron, 1999; Robine and Romieu, 1998). Particularly, increased levels of disability with advancing age as well as clear gender differences have been reported. Females generally tend to outlive males but are more likely to live a greater part of their remaining life in disability. Such differentials have been attributed in part to key socioeconomic factors including the mediating effect of education and income (Maddox and Clark, 1994). Low income and low occupational status were found to account largely for women's lower self-rated health (Ross and Bird, 1994 in Peek et al. 1999). Gender variations may be traced in part to measurement bias. For example, some studies identify the gendered nature of certain instrumental activities of daily living (IADL) tasks, a set of activities used to gauge functional ability, as a possible cause of differences in ALE between males and females (Allen, Mor, Ravis and Houts, 1993 in Peek et al. 1999). A recent study on the ALE in the Philippines shows females with significantly higher proportion of ALE (Ofstedal, et al, 2004). 
Grace T. Cruz, Yasuhiko Saito and Josefina N. Natividad

A small but growing body of literature demonstrates higher education to be associated with better functioning (Camacho et al. 1993; Crimmins and Saito, 2001; Land et al. 1994; Meng-Fan Li, 2003). In the U.S., findings indicate initial signs of a compression of morbidity or a shortening of the period between final illness and death, for those of higher educational status while those in the lower education are still experiencing an expansion of morbidity (Crimmins and Saito, 2001). The mechanism by which education impinges on health is manifested through its impact on lifestyle and health behaviors. Low levels of education appear to influence behaviors that are significantly associated with adverse health outcomes (Haveman and Wolfe, 1984). In particular, people with lower SES who are also more likely to have low education are more likely to have greater exposure to a wider range of risk factors such as smoking, alcohol drinking, lack of exercise, and work hazards, factors whose effects are cumulative over a lifetime and may manifest in functional health problems at old age.

While advancing age may be associated with a higher likelihood of disability the process of decline in health is not irreversible. Studies on health dynamics cite significant evidence of recovery from disability among older people. In Japan approximately 30 per cent of older people who were in a state of disability in 1987 regained their functional ability during the following three years (Liu et al. 1995). A similar study among American older people reported a 20 per cent recovery rate within a two year period (Rogers, Rogers and Belanger, 1990) although these levels should not be compared given the differences in measures and time frames. In Taiwan, recent finding shows a declining rate of recovery from inactive state as age increases with the males more likely to exhibit higher levels of recovery (Meng-Fan Li, 2003). A host of socioeconomic and environmental factors were found to explain health recovery including age, participation in organizational activities, social support and self-rated health. In particular, younger age and better self-rated health may influence health status by reducing the risk of becoming disabled or dying and by facilitating recovery (Liu et at, 1995). The same study shows lower education, not being married and smoking may increase the risk of disability, but they do not have a negative effect on recovery.

\section{Subjects and Methods}

Data for the study came from the 2000 Philippine Follow-up Survey on the Elderly (alternatively referred herein as the Panel Study). This study is a followup of a sub sample of respondents interviewed in the 1996 Philippine Elderly Survey (PES) covering a representative sample of older Filipinos 50 years and higher. The follow-up study covered two out of five original areas of the 1996 
PES namely Metro Manila (NCR) and the province of Leyte, which together account for 46 percent of the total respondents in the 1996 PES (Natividad and Cruz, 2002). Metro Manila was selected to represent the highly urban sample while Leyte represents a combination of both urban and rural. The same survey instrument was used in both surveys with minor additions in the follow-up questionnaire. A total of 932 respondents from the 1996 PES were tracked down for a follow-up interview from 2000 to 2002 for the panel study. Of this number, 68.9 per cent were successfully interviewed, 18.1 per cent died and 13 per cent were lost to follow-up.

For those who were reported to have died at follow-up, mortality data came from interviews of surviving family members, neighbors and friends who were knowledgeable of the circumstances of the older person's death. Information was gathered on the date and place of death, the cause of death and the health services received by the respondent prior to death. Among those who were reported lost to follow-up, validation with the death registry of the National Statistics Office was conducted to verify whether the respondent who could not be located had actually passed away. Through this procedure we were able to improve our estimate of mortality.

Respondents who were no longer living in their original residence in 1996 were tracked down during the follow-up survey. In general, those who moved within a reasonable distance from the original address or within the study areas were located and interviewed.

\section{Measurement}

Definition of Health Status. In order to estimate Active Life Expectancy (ALE), health status is defined in terms of functioning ability based on ADLs and IADLs ${ }^{1}$. A composite index combining ADLs and IADLs is expected to enhance the range and sensitivity of health measurement as compared to those limited to either ADL or IADL indicators only (Spector and Fleishman, 1998).

\section{Explanatory Variables}

In order to examine predictors of change in health status over the two survey dates, three sets of explanatory variables were used namely, demographic, socioeconomic and health behavior/self-assessed health. The explanatory variables refer to information taken in 1996. 
Grace T. Cruz, Yasuhiko Saito and Josefina N. Natividad

The demographic characteristics are age, sex and place of residence. Place of residence is categorized into urban and rural residence with the assumption that the different social settings represent differences in lifestyle patterns and access to health facilities. Urban areas are normally associated with better level of health services while the rural setting is associated with lower incomes and poorer health access (Eberhardt et al. 2001, Zimmer et al. 1999).

Education is used as an indicator of socioeconomic status. The education variable was operationalized based on the 1996 PES sample distribution that showed elementary education as the modal highest educational attainment. Accordingly, education is categorized into those with high school and less than high school or elementary education (meaning six years of schooling or less).

A number of health-related explanatory variables are used in the study. These are self-rated health, exercise and two health risk behaviors, smoking and drinking. Smoking and drinking are defined in terms of health risk behavior in 1996 (currently drinking or smoking vs. not currently smoking or drinking during the 1996 survey). The exercise variable has two categories: those who engaged in physical exercise at least weekly and those who did so less frequently or not at all. Self-assessed health is categorized into those who perceived their health to be poor and those who assessed their health as not poor (i.e. fair, good, very good or excellent).

Data Analysis. Our analysis involves two parts. First, we examined the health transition patterns and the factors that determine these health transitions using a multinomial logistic regression analysis (MNLA) and a multiple classification analysis (MCA). Second, ALE was estimated by selected background variables based on a multistate life table method (MSLT).

For the MSLT method, there are four possible health transitions emanating from two initial health states (active or inactive): active to inactive; active to dead; inactive to active; inactive to dead) and the two retention statuses, (active to active; inactive to inactive). This multi-state approach for computing ALE was performed with the aid of a computer program called $\mathrm{IMaCH}$ (version 0.96), a maximum Likelihood Computer Program using Interpolation of Markov Chains developed by Brouard and his colleagues at INED (Lievre and Brouard, 2003) and using methodologies pioneered by Laditka and Wolf (1998).

The IMaCH assumes that age-related changes in health are governed by a Markovian process. Under the Markov assumption, an unhealthy male or female at any age has at least a probability of returning to the healthy state with the probability of recovery being independent of either the duration of the current episode of poor health or the occurrence of prior episodes of poor health 
(Laditka and Hayward, 2003). The basic methodology of IMaCH is multinomial logistic regression model to generate health transition probabilities. It produces outputs of total life expectancy and health expectancy with standard errors of the estimates.

IMaCH computes for both the population and status-based life table estimates. Population-based tables describe the potential life cycle events for the whole population while the status-based tables can be used to compare the prospective life cycles of those who reach specified ages in different health states (Saito, Crimmins and Hayward, 1999).

For the MNL analysis, two separate models of health transition were considered, each emanating from either of two initial health states: active or inactive. For both models, the reference category was "those who retained their initial health state." Four states are considered at follow-up: active, inactive, dead and lost to follow up. Although "lost to follow-up" is not a health outcome, it was included in the modeling and treated as a separate category to include all possible trajectories that the respondents in the initial study may take so as to avoid bias in the estimate. A multiple classification analysis (MCA) was employed to show the marginal effects of the independent variables for each of the transitions. The multinomial logistic regression analysis was performed using the STATA program (version 8 ).

\section{Results}

\section{Health Transition Patterns and Differentials}

Differences by Sex and Initial Health State. Table 1 presents the distribution of respondents by initial health status in 1996 and health status at follow up for those age 50 and above in 1996. The results show that there is significant movement in and out of one's initial health. There is particular evidence of significant recovery from inactive status suggesting that aging does not unequivocally mean a progressive physical decline. The high rate of recovery noted in the country that has been established in this study particularly among the females $(25.5 \%)$ suggests the need to take this factor into account if a more realistic estimate of functional health transition is to be achieved and that completely ignoring the possibility of recovery from disability can be highly misleading (Liu et al. 1995).

Initial health status poses a significant influence on future health prospects. Specifically, inactive health status is associated with greater likelihood of experiencing mortality and health change over time. Those who are initially 
Grace T. Cruz, Yasuhiko Saito and Josefina N. Natividad

inactive are three times more likely to experience mortality compared to those who are initially active. Those with health impairments at the beginning are also likely to remain the same over time with the inactive females more likely to report no change in functional health status relative to males. This, coupled with the female's lower mortality help explain their increased chance of experiencing more of their remaining years in an inactive state. The good news is that the majority of those active are likely to remain active. Compared to those initially inactive, they are also less likely to experience disability and mortality at the second point in time. They are also more likely to be lost to follow-up that is expected given that they are more mobile than those who were initially in an inactive state.

Table 1

Health Transitions among Filipino Older People 50 and over by Initial Health State and Sex for the Philippines: 1996 and 2000

\begin{tabular}{lccccc}
\hline Sex and Age & Active & Inactive & Dead & $\begin{array}{c}\text { Moved/Lost } \\
\text { to follow-up }\end{array}$ & Total (N) \\
\hline $\begin{array}{l}\text { Both Sexes } \\
\text { Active }\end{array}$ & 57.6 & 15.4 & 13.8 & 13.2 & $100(622)$ \\
$\begin{array}{l}\text { Inactive } \\
\text { Males }\end{array}$ & 22.8 & 30.3 & 38.6 & 8.3 & $100(145)$ \\
$\quad$ Active & 57.7 & 13.5 & 16.8 & 11.8 & $100(279)$ \\
Inactive & 16.0 & 26.0 & 50.0 & 8.0 & $100(50)$ \\
$\begin{array}{l}\text { Females } \\
\text { Active }\end{array}$ & & & & & \\
Inactive & 57.4 & 16.9 & 11.1 & 14.6 & $100(343)$ \\
& 25.8 & 33.3 & 33.3 & 7.5 & $100(93)$ \\
\hline
\end{tabular}

Determinants of Health Transition. As shown in the bottom panel of Table 2, majority of those who reported being active in 1996 did not experience a change in their health status within the 4-year observation period. Among the initially active, 57 per cent remained active, 16 per cent became inactive, 13 per cent died and 15 percent were lost to follow-up. For the initially inactive the bottom panel of Table 3 shows the proportion in each transition state. The initially inactive were more likely to die (39.9\%) but less likely to be lost to follow-up 
(7.6\%). Those who remained inactive constituted 31 per cent of cases while 25.1 per cent recovered from an initial inactive state.

Table 2

Results of Multinomial Logistic Regression:

Marginal Effects of Explanatory Variables on Transition Probabilities of Functional Status among those who were Active at Initial State

\begin{tabular}{|c|c|c|c|c|}
\hline \multirow{2}{*}{$\begin{array}{l}\text { Explanatory Variables } \\
\text { Baseline Characteristics }\end{array}$} & \multicolumn{4}{|c|}{ Transition from Active } \\
\hline & $\begin{array}{c}\text { To } \\
\text { Active }\end{array}$ & $\begin{array}{c}\text { To } \\
\text { Inactive }\end{array}$ & Dead & $\begin{array}{c}\text { To Lost } \\
\text { to follow-up }\end{array}$ \\
\hline Age & & $0.01 * *$ & $0.01 * *$ & \\
\hline Male $($ Male $=1)$ & & & $0.13 * *$ & \\
\hline Urban $($ Urban $=1)$ & & $0.09 *$ & $0.03 *$ & $0.12 * *$ \\
\hline Education (High School = 1) & & & & \\
\hline $\begin{array}{l}\text { Smoking } \\
\quad(\text { currently smoking }=1)\end{array}$ & & & & \\
\hline $\begin{array}{l}\text { Drinking } \\
\quad(\text { currently drinking }=1)\end{array}$ & & & $-0.13 * *$ & \\
\hline $\begin{array}{l}\text { SAH } \\
(\text { good or better }=1)\end{array}$ & & & $-0.11^{*}$ & \\
\hline $\begin{array}{l}\text { Exercise } \\
\quad(\text { exercise at least weekly }=1)\end{array}$ & & $-0.05^{*}$ & & \\
\hline Sample Estimate & .567 & .155 & .129 & .149 \\
\hline
\end{tabular}

Table 2 shows the marginal effect of each explanatory variable on the transition probability among the initially active. Only significant predictors are shown. Results indicate the significant effect of age, gender, place of residence, drinking behavior, exercise and self-assessed health status on the health and mortality transitions. Education does not appear to have a significant effect.

For those active, each additional year resulted in a 1 per cent increase in the probability of transitioning to inactive state and to death. Males are 13 percent more likely to die than females. Findings show an urban disadvantage with urban residents 3 per cent more likely to experience mortality and 9 per cent 
Grace T. Cruz, Yasuhiko Saito and Josefina N. Natividad

more likely to experience health decline compared to rural residents. Current drinkers in 1996 were less likely to die compared with those who were not currently drinking while those who had a positive self assessment of health status were less likely to die. The latter confirms previous findings showing self assessed health to be a strong predictor of mortality (Ofstedal et al. 2002; Idler and Kasl, 1991; Idler and Angel., 1990). Engaging in physical exercise also showed a protective effect against functional health decline. Among those initially active, those who reported exercising regularly in 1996 were 5 per cent less likely to become inactive in the follow-up period.

As shown in Table 3, among those classified as inactive in 1996, each additional year translates to a 2 per cent decline in their chances for recovery and another 2 per cent increased risk of mortality. Inactive males also exhibit a 34 per cent higher risk of experiencing mortality than their female counterparts. Urban older people are less likely to bounce back to active state while those with good self assessment of health status register a 21 per cent increased chance of recovery. Results also show the better educated are less likely to be lost to follow-up compared to those with less education.

Overall, results show a consistent gender effect on the risk of dying over the 4year period with the males more likely to die regardless of health state. However, there is no effect of gender on the type of transitions experienced over the same period. Only age showed a consistent significant effect on both health and mortality transitions.

\section{Differentials in ALE (Multistate Life Table Method)}

Given the statistically significant effect of sex and place of residence on several health and mortality transitions from MNLA, we estimated active life expectancies using IMaCh with sex and place of residence as the only covariate other than age. Results in Tables 4 and 5 show the population-based estimates of total, active, and inactive life expectancies, including their standard errors by sex and place of residence, respectively.

Estimated life expectancies by sex shows that female older people are expected to live longer lives but spend more years and a greater proportion of their remaining life in an inactive state. In terms of place of residence, rural residents generally expect to live longer and to spend a relatively lower proportion of that time in an unhealthy state. A 60 year old rural resident for example can anticipate to live almost 15 more years on the average, 1.5 years longer than an urban resident of the same age, 26 per cent of which will be lived in an 
unhealthy state while the comparable percentage for the urban resident is 43 per cent. This urban-rural disparity widens with advancing age.

Table 3

Results of Multinomial Logistic Regression:

Marginal Effects of Explanatory Variables on Transition Probabilities of Functional Status among those who were Inactive at Initial State

\begin{tabular}{|c|c|c|c|c|}
\hline \multirow{2}{*}{$\begin{array}{l}\text { Explanatory Variables } \\
\text { Baseline Characteristics }\end{array}$} & \multicolumn{4}{|c|}{ Transition from Inactive } \\
\hline & $\begin{array}{c}\text { To } \\
\text { Active }\end{array}$ & $\begin{array}{c}\text { To } \\
\text { Inactive }\end{array}$ & Dead & $\begin{array}{c}\text { To Lost } \\
\text { to follow-up }\end{array}$ \\
\hline Age & $-0.02 *$ & & $0.02 * *$ & \\
\hline Male $($ Male $=1)$ & & & $0.34 * *$ & \\
\hline Urban $($ Urban $=1)$ & $-0.21 *$ & & & \\
\hline $\begin{array}{l}\text { Education }(\text { High School }=1) \\
\text { Smoking } \\
\quad(\text { currently smoking }=1)\end{array}$ & & & & $-0.11 *$ \\
\hline $\begin{array}{l}\text { Drinking } \\
\quad(\text { currently drinking }=1)\end{array}$ & & & & \\
\hline $\begin{array}{l}\text { SAH } \\
(\text { good or better }=1 \text { ) }\end{array}$ & $0.21 *$ & & & \\
\hline $\begin{array}{l}\text { Exercise } \\
\quad(\text { exercise at least weekly }=1)\end{array}$ & & & & \\
\hline Sample Estimate & 0.251 & 0.310 & 0.399 & 0.076 \\
\hline
\end{tabular}

\section{Discussion}

In the Philippines, the concept of health expectancy and active life expectancy are relatively new. Only two previous explorations in HE have been conducted prior to this study including an inter-country comparison in HE using ADL indicators from the 1984 WHO data (Lamb, 1999) and the self-assessed health measure using the 1996 Philippine Elderly Survey (PES) (Ofstedal et.al. 2004). Both studies made use of the Sullivan method to measure ALE. 
Grac T. Cruz,Yasuhiko Saito and Josefina N. Natividad

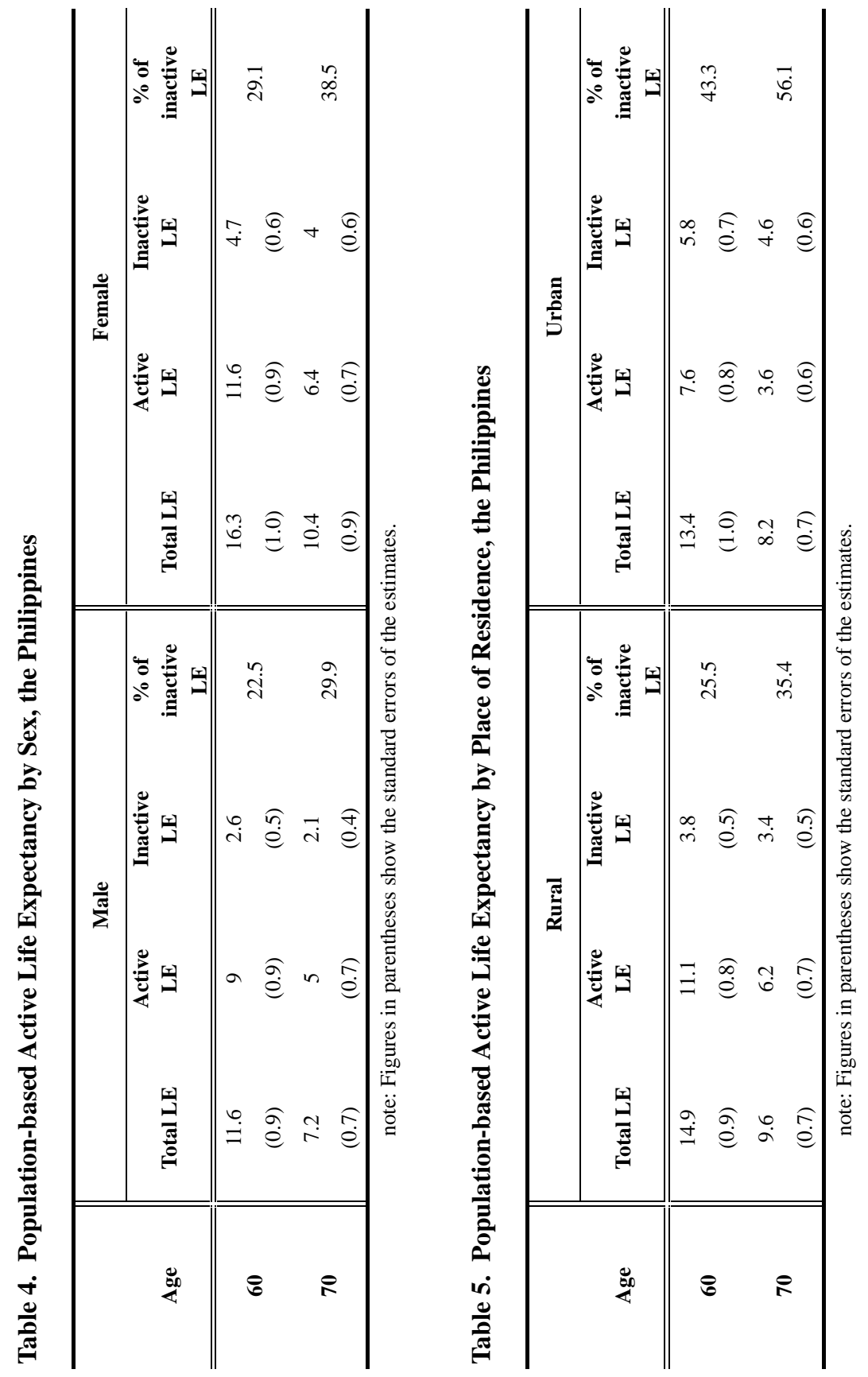

CSP 2007; 34.1: 29-47 
In this analysis of ALE using multistate life table method we found that the number and proportion of healthy years relative to total remaining life years decline with age for both sexes. Females are more likely to outlive males but can expect to live a greater part of that remaining life in a state of functional impairment. These findings generally conform with those reported in the literature on aging and health in other countries. The consistency between the study results using ADLs and IADLs with other studies which made use of other objective and well-established health indicators implies that such functional measures are picking up the health transitions by age and sex in the local population. This suggests the appropriateness in using ADLs and IADLs as health measure for elderly research in developing countries such as the Philippines.

The study findings further demonstrate that as we anticipate future expansions in the size of the older population, a corresponding increase in the projected number with disability is expected, more for females than males. The expected declines in functional health (specifically, in the ability to perform normal, everyday activities of daily living ) can result in significant restrictions on life styles, modifications in recreational and leisure activities, social isolation, poor nutrition and overall decrease in the quality of life (Kiyak and Borson, 1992; Verbrugge and Jette, 1994). Future policies should thus be able to respond to such eventuality by articulating appropriate mechanisms of response, particularly the provision of health services, health insurance and social security for the anticipated increase in the number of inactive older people in need of support. This is important in the light of current conditions of very limited government resources and where the health infrastructure has generally been oriented towards infectious diseases and maternal and child health making it less equipped to handle the health requirements of older people (Hermalin, 2003). It is particularly important to address the needs of women who expect to longer period of life spent in disability before death.

One finding that needs further study is the rural-urban differential in ALE and health transitions. Generally we found that urban residents expect to live fewer years and to spend a higher proportion of those years in an unhealthy state compared with rural residents. Apparently, being an urban resident puts an older person at a disadvantage in general. It is also a risk factor for transitioning to an unhealthy state or to death among those who start out from an active state while it is associated with a diminished probability of recovery among those who are inactive. Similar findings of an urban-rural differential in Thailand and China (Jitapunkul et al. 1999 cited in Saito, 2003; Wang, 1993 cited in Saito, 2003) suggest that urbanization in developing country settings may have an adverse effect on active life expectancy. It is thus significant to understand the mechanisms that underlie such a finding. It is particularly interesting to 
Grace T. Cruz, Yasuhiko Saito and Josefina N. Natividad

understand the extent to which rapid and uncontrolled pace of urbanization particularly the overcrowding in informal settlements affect the health of older people. On the other hand, do values of strong family solidarity and harmonious community relationships that continue to prevail in many traditional communities in the country contribute in the preserving the good health of the rural elderly?

One possible explanation for the observed rural-urban differences on the older persons' health is the urban ward migration of older people for health reasons thus raising the levels of disability in urban areas. This in turn may have been reinforced by the differential access in health care with the greater concentration of major health facilities in urban centers and the relatively poor access in many remote rural areas (Favereau, 1993; Zimmer et al., 2000).

Our analysis of factors that affect specific health transitions show that when controlling for initial health state age, gender and other health indicators including drinking, exercise and self-assessed health effects remain. Exercise figures as a significant protective factor of an active person's risk of transitioning to an inactive state. In addition, drinking showed a significant negative effect on the risk of dying. Although seemingly counterintuitive, the negative association between current drinking and the risk of death is actually not unexpected. Those who were not currently drinking included a large proportion who have stopped drinking because of health reasons and being in poorer health predisposed them to death more than current drinking did. Those who were currently drinking could have been a healthier lot. Such finding is relevant in the light of growing evidence showing early exposure of Filipinos to drinking (Domingo and Marquez, 1999).

These findings suggest the role of lifestyle change in any future intervention program designed to increase active life expectancy among older people in the Philippines. Findings of a significant effect of self-assessed health on the risk of death (among the healthy) and the risk of recovery (among unhealthy) also support previous findings showing self assessed health to be a strong predictor of mortality (Ofstedal. 2004), and health status.

What is somewhat unexpected is the nonsignificant effect of education on the health transitions. Although this is inconsistent with statistically significant effect of education on ALE in many settings (Peek et al. 1997), this is consistent with the result of a similar study reporting in the Philippines showing a weak link between education and measures of functional health (Zimmer,et.al., 2000). There is a need to verify the study results with other data sets particularly since the standard errors of the estimates are large because of the small sample size and missing cases. 
The study findings have significant implications on the country's policy for older people that today has largely centered on the need to provide for health care in the form of curative services. The most significant provision in the Senior Citizens' Act (Republic Act 7432) of 1992 has been the grant of a 20 per cent discount on medicines for older people, age 60 and over- regardless of socioeconomic status. This works to the benefit of older people who have the means to purchase medicines in the first place but have no beneficial effect on those who can not afford to buy medication at all. A recently passed supplementary law to the Senior Citizens Act, RA 9257, the Expanded Senior Citizens Act of 2003 grants additional benefits that essentially expands the medical cost provisions. Specifically RA 9257 exempts the elderly from diagnostic and laboratory fees from government health centers in addition to other provisions. While such policy has the potential to provide economic relief to older people who face the burden of increased medical costs at a time when their earning capacity has diminished and there are no social safety nets other than the family to shoulder the cost of health care it fails to conceive of the issue of elderly health as more than just a medical one.

Our findings on active life expectancy demonstrate that prolonging life may only mean prolonging an unhealthy life. Thus there is a need to consider the quality of life issue when policies about older people are drawn. For example, our findings underscore that promoting lifestyle change in general may be a useful addition to existing government programs to improve elderly health. Rather than simply offering ways to alleviate the cost of curative care, promotion of behaviors that are preventive in nature may go a longer way in improving elderly health and increasing active life expectancy.

The study has certain limitations. First is the much lower estimated total life expectancies compared to the published life tables. This is attributed to the problems in the data set. As noted earlier, the panel data covered only 2 of the 5 sample regions included in the first nationally representative survey. This resulted in a limited sample size to permit a more sophisticated levels of analysis particularly examining the ALE at the national level and for certain subgroups of the population.

As in any longitudinal study, attrition of cases posed a limitation on the data. Loss to follow-up was largely due to migration and outright refusal. This problem persisted despite the various strategies employed to minimize it including tracking down respondents who were originally reported to have moved out from their original place of residence and by tracing possible mortality cases among those lost to follow-up. The fact that the original survey design was not planned as a longitudinal survey likewise contributed to the 
Grace T. Cruz, Yasuhiko Saito and Josefina N. Natividad

attrition problem. Despite data limitation, our findings generally conform with those reported in the aging literature thus lending support to our contentions that no serious flaws in the data resulted from the high attrition. Finally, the study demonstrated the feasibility of using panel studies in a developing country with no formal means to track the citizens. Future panel studies will benefit from the finding of this first attempt at this methodology as well as this first application of the ALE concept to aging research in the Philippines.

\section{Acknowledgements:}

Paper presented at the Conference of the Federation of Canadian Demographers on Longitudinal Studies and Demographic Challenges of the 21st Century Université de Montréal, 18-19 November 2005

This study was partially supported by the University of the Philippines Office of the Vice-chancellor for Research and Development Ph.D. Incentive Award NIA funded 'Aging and Health in Asia' Project of the University of Michigan Population Studies Center and the 'MEXT Academic Frontier Project of the Nihon University Population Research Institute.

\section{End Notes:}

1. Indicators of Activities of Daily Living (ADL) in the survey were walking around the house, eating, putting on clothes/dressing, and taking a bath/going to bathroom while Instrumental Activities of Daily Living (IADL) were preparing own meal, shopping for groceries or personal items, managing own money, doing light housework, and using transportation. A person is classified as being in an active state if he/she has not reported difficulty with any of the ADL or IADL measures while in inactive state if he/she has indicated difficulty in performing any ADL or IADL measures. For purposes of this study, we refer to the healthy as active and the unhealthy as inactive

\section{References:}

Camacho, T. C., Strawbridge, W.J., Cohen, R. D. \& Kaplan, G. A. (1993). "Functional Ability in the Oldest Old: Cumulative Impact of Risk Factors from the Preceding Two Decades," Journal of Aging and Health, 5: 43954. 
Crimmins, E. \& Saito, Y (2001). "Trends in Disability-free Life Expectancy in the United States, 1970-1990. Gender, Racial, and Socioeconomic Differences," Social Science and Medicine 52(11): 1629-1641.

Crimmins, E., M. D. Hayward, and Y. Saito (1996). "Differentials in Active Life Expectancy in the Older Population of the United States," Journal of Gerontology: Social Sciences, Vol. 51B, No. 3, S111-S120.

Domingo, L. J, \& Marquez, M.P. (1999). Smoking, Drinking and Drug use. In C. M. Raymundo, P. Xenos and L. J. Domingo (Eds.) Adolescent Sexuality in the Philippines (pp. 70-80). Quezon City, Philippines.

Eberhardt, M.S., Ingram, D.D. \& Makuk, D.M. (2001). Urban and Rural Health Chartbook, Health, US, 2001. Hyattsville, Maryland: National Center for Health Statistics.

Favereau, F. 1993. Healthcare Handbook: vol 1.4, Philippines. Langon, France:F Favereau and Associates.

Haveman, R. H. \& Wolfe, B. (1984). "Schooling and Economic Well-being: The Role of Nonmarket Effects," Journal of Human Resources 19(summer): 378-407.

Hayward, M. D. \& Heron, M. (1999). "Racial inequality in active life among adult Americans," Demography 36(1): 77-91.

Hermalin, A. I. (2003). The Well Being of the Elderly in Asia: A Four-Country Comparative Study. Ann Arbor, Michigan: University of Michigan Press.

Idler, Ellen L. and Ronal J. Angel (1990). "Self-rated Health and Mortality in the NHANES-1 Epidemiologic Follow-up Study." American Journal of Public Health 80(4): 446-452.

Idler, Ellen L. and Stanislav V. Kasl (1991). "Health Perceptions and Survival: Do Global Evaluations of Health Status Really Predict Mortality?" Journal of Gerontology 46(2): S55-S65.

Kiyak, H. A. \& Borson, S. (1992). Coping with Chronic Illness and Disability. In M. G. Ory, R. P. Abeles and P. D. Lipman (Eds.), Aging, Health and Behavior. Newbury Park, CA: Sage Publications. 
Grace T. Cruz, Yasuhiko Saito and Josefina N. Natividad

Lamb, V. L. (1999). Active Life Expectancy of the Elderly in Selected Asian Countries, NUPRI Research Paper Series No. 69. Tokyo: Nihon University Population Research Institute.

Land, K. C., Guralnik, J.M. \& Blazer, D. G. (1994). "Estimating incrementdecrement life tables with multiple covariates from panel data: The case of active life expectancy," Demography, 31:297-319.

Latidka, S. B. \& Hayward, M. D. (2003). The Evolution of Demographic Methods to Calculate Health Expectancies. In J. M. Robine, C. Jagger, C. D. Mathers, E. M. Crimmins, and R. Suzman (eds.), Determining Health Expectancies (pp. 221-234). West Sussex, England: John Wiley and Sons, Ltd..

Latidka, S. B. \&. Wolf, D. A (1998). "New methods for analyzing active life expectancy," Journal of Aging and Health, 10: 214-241.

Lieve,A. \& N. Brouard (2003). "The Estimation of Health Expectancies from Cross-Longitudinal Surveys," Mathematical Population Studies, 10: 211248.

Li, Meng_Fan (2003). Health Status and Health Expectancy for the Elderly in Taiwan from 1989 to 1999 . Unpublished doctoral dissertation, University of South Carolina, USA.

Liu,X., Liang, J., Muramatsu, N. \& Sugisawa, H. (1995). “Transitions in functional status and active life expectancy among older people in Japan,” Journal of Gerontology: Social Sciences, 50B(6): S383- S394.

Natividad J. \& Cruz, G. (2002). A Feasibility Study on the Use of the Panel Design for the Study of the Elderly and the Course of Aging in the Philippines: The Visayan Sample. Report submitted to the CIDS, University of the Philippines, Diliman.

Olshansky, S. Jay and Brian Ault B. (1986). "The Fourth Stage of the Epidemiologic transition: The age of Delayed and Degenerative Diseases," The Milbank Quarterly, 64 (3): 355-391.

Ofstedal, M. B., Zimmer, Z., Cruz, G., Chan, A. \& Lin, Y.H. (2004). "Selfassessed health expectancy among older adults: A comparison of six Asian settings," Hallym International Journal of Aging. 6(2): 95-117. 
Peek K. M. \& Coward, R. T. (1999). "Gender Differences in the Risk of Developing Disability Among Older Adults With Arthritis," Journal of Aging and Health, 11(2): 131-150.

Robine, J-M. \& Romieu, I. (1998). Healthy Active Aging: health expectancies at age 65 in the different parts of the world. Montpellier: REVES/INSERM, REVES paper 318.

Rogers, A, Rogers, R. G. \& Belanger, A. (1990). "Longer Life but Worsening Health? Measurement and Dynamics," The Gerontologist, 30: 640-649.

Saito, Y., E. M. Crimmins and Hayward, M. D. (1999). Health Expectancy: An Overview, NUPRI Research Paper Series No. 67. Tokyo: Nihon University Population Research Institute.

Saito, Y., Qiao, X \& Jitapunkul, S. (2003). Health Expectancy in Asia. In J.M. Robine, C. Jagger, C. D. Mathers, E. M. Crimmins, \& R. Suzman (eds.). Determining Health Expectancies (pp. 289-318). West Sussex, England: John Wiley and Sons, Ltd.

Verbrugge, L.M. \& Jette, A. (1994). The Disablement Process. Social Science and Medicine, 38: 1-14.

Verbrugge, L.M. (1984). "Longer life but worsening health? Trends in health and mortality of middle-aged and older persons," Milbank Memorial Fund Quarterly/Health and Society, 62(3): 475-519.

Zimmer, Z., Natividad, J., Lin, H.S. \& Chayovan, N. (2000). “A Crossnational Examination of the Determinants of Self- Assessed Health," Journal of Health and Social Behavior, 41: 465-481.

Zimmer, Z., Natividad, J.,. Ofstedal, M. B \& Lin, H. (2002). Physical and mental health and well-being. In A. I. Hermalin (ed), The Well-being of the Elderly in Asia: A four-country Comparative Study. Ann Arbor, Michigan: University of Michigan Press. 